\title{
Erratum to: Transcriptional effect of a calmodulin inhibitor, W-7, on the ligninolytic enzyme genes in Phanerochaete chrysosporium
}

Takaiku Sakamoto $\cdot$ Hironori Kitaura $\cdot$ Masahiko Minami

Yoichi Honda $\cdot$ Takashi Watanabe $\cdot$ Akio Ueda

Kazumi Suzuki · Toshikazu Irie

Published online: 5 August 2010

(C) Springer-Verlag 2010

\section{Erratum to: Curr Genet}

DOI 10.1007/s00294-010-0309-z

In the original publication of the article, under "Discussion" section (paragraph 5), the text "and that the cAMP concentration and the activities were repressed when a reactive oxygen species inhibitor was used (Belinky et al. 2003)" should read as "and that Belinky et al. also observed an increase of cAMP concentration during the enzyme expression period (Belinky et al. 2003)".

The online version of the original article can be found under doi:10.1007/s00294-010-0309-z.

T. Sakamoto $\cdot$ H. Kitaura $\cdot$ A. Ueda $\cdot$ K. Suzuki $\cdot$ T. Irie $(\bowtie)$

Environmental Science Graduate School,

The University of Shiga Prefecture, 2500 Hassaka-cho,

Hikone, Shiga 522-8533, Japan

e-mail: tirie@ses.usp.ac.jp

M. Minami · Y. Honda $\cdot$ T. Watanabe

Research Institute for Sustainable Humanosphere,

Kyoto University, Gokasho, Uji, Kyoto 611-0011, Japan 